\title{
Mild cognitive impairment in Parkinson disease
}

\author{
A multicenter pooled analysis
}

D. Aarsland, MD

K. Bronnick, PhD

C. Williams-Gray, MRCP, PhD

D. Weintraub, MD

K. Marder, MD

J. Kulisevsky, MD

D. Burn, MD

P. Barone, MD

J. Pagonabarraga, MD

L. Allcock, MD

G. Santangelo, PhD

T. Foltynie, $\mathrm{PhD}$

C. Janvin, PhD

J.P. Larsen, MD

R.A. Barker, MRCP, $\mathrm{PhD}$

M. Emre, MD

Address correspondence and reprint requests to Dr. Dag Aarsland, Stavanger University Hospital, Psychiatric Division, PO Box 8100, 4068 Stavanger, Norway

daarsland@gmail.com

\section{Editorial, page 1038}

Supplemental data at www.neurology.org

\section{ABSTRACT}

Background: In studies of mild cognitive impairment (MCI) in Parkinson disease (PD), patients without dementia have reported variable prevalences and profiles of $\mathrm{MCl}$, likely to be due to methodologic differences between the studies.

Objective: The objective of this study was to determine frequency and the profile of $\mathrm{MCl}$ in a large, multicenter cohort of well-defined patients with PD using a standardized analytic method and a common definition of $\mathrm{MCl}$.

Methods: A total of 1,346 patients with PD from 8 different cohorts were included. Standardized analysis of verbal memory, visuospatial, and attentional/executive abilities was performed. Subjects were classified as having $\mathrm{MCl}$ if their age- and education-corrected $z$ score on one or more cognitive domains was at least 1.5 standard deviations below the mean of either control subjects or normative data.

Results: A total of $25.8 \%$ of subjects (95\% confidence interval [CI] 23.5-28.2) were classified as having $\mathrm{MCl}$. Memory impairment was most common (13.3\%; 11.6-15.3), followed by visuospatial (11.0\%; 9.4-13.0) and attention/executive ability impairment (10.1\%; 8.6-11.9). Regarding cognitive profiles, $11.3 \%$ (9.7-13.1) were classified as nonamnestic single-domain $\mathrm{MCl}, 8.9 \%$ (7.0-9.9) as amnestic single-domain, 4.8\% (3.8-6.1) as amnestic multiple-domain, and 1.3\% (0.9-2.1) as nonamnestic multiple-domain $\mathrm{MCl}$. Having $\mathrm{MCl}$ was associated with older age at assessment and at disease onset, male gender, depression, more severe motor symptoms, and advanced disease stage.

Conclusions: $\mathrm{MCl}$ is common in patients with $\mathrm{PD}$ without dementia, affecting a range of cognitive domains, including memory, visual-spatial, and attention/executive abilities. Future studies of patients with PD with $\mathrm{MCl}$ need to determine risk factors for ongoing cognitive decline and assess interventions at a predementia stage. Neurology ${ }^{\circledR} 2010 ; 75: 1062-1069$

\section{GLOSSARY}

aMCI-MD = amnestic multiple-domain MCl; aMCI-SD = amnestic single-domain $\mathbf{M C l} ; \mathbf{C I}=$ confidence interval; $\mathbf{D S M}-\mathbf{I V}=$ Diagnostic and Statistical Manual of Mental Disorders, 4th edition; $\mathbf{M C l}=$ mild cognitive impairment; $\mathbf{M M S E}=\mathbf{M i n i}-\mathrm{Mental}$ State Examination; naMCI-MD = nonamnestic multiple-domain $\mathrm{MCl}$; naMCI-SD = nonamnestic single-domain $\mathrm{MCl}$; PD = Parkinson disease; PD-CRS = Parkinson's Disease Cognitive Rating Scale; UPDRS = Unified Parkinson's Disease Rating Scale.

Dementia is often associated with Parkinson disease (PD), especially in the late stages. Cognitive impairment of a lesser severity is also common in patients with PD without dementia, designated as mild cognitive impairment (MCI) of PD, or PD-MCI. Patients with PD with MCI have an increased risk of developing dementia, compared with those without. ${ }^{1-3}$ Previ-

From the Psychiatric Division (D.A., C.J.) and The Norwegian Centre for Movement Disorders (K.B., J.P.L.), Stavanger University Hospital, Stavanger; Division of Mental Health Services (D.A.), Akershus University Hospital, and University of Oslo, Oslo, Norway; Centre for Brain Repair (C.W.-G., R.A.B.), Department of Clinical Neurosciences, University of Cambridge, Cambridge, UK; Department of Psychiatry and Neurology (D.W.), University of Pennsylvania, Philadelphia; Parkinson's Disease and Mental Illness Research, Education and Clinical Center (PADRECC and MIRECC), Philadelphia Veterans Affairs Medical Center, Philadelphia, PA; Department of Neurology (K.M.), Columbia University College of Physicians and Surgeons, New York, NY; Movement Disorders Unit (J.K., J.P.), Neurology Department, Sant Pau Hospital, Autonomous University of Barcelona and CIBERNED (Centro de Investigaciones Biomédicas en Red Enfermedades Neurodegenerativas), Barcelona, Spain; Institute for Ageing and Health (D.B., L.A.), Newcastle University, Newcastle, UK; Department of Neurological Sciences-ICD Hermitage Capodimonte (P.B., G.S.), Naples, Italy; Sobell Department of Motor Neuroscience and Movement Disorders (T.F.), Institute of Neurology, University College London, UK; and Istanbul University (M.E.), Istanbul Faculty of Medicine, Department of Neurology, Behavioural Neurology and Movement Disorders Unit, Istanbul, Turkey.

Study funding: Supported by an unrestricted grant from Merck Serono.

Disclosure: Author disclosures are provided at the end of the article. 
ously, a variety of definitions for MCI in PD have been used, based on the type and number of cognitive tests administered, and how impairment was defined. In addition, factors including study design, methodology, and the patient cohort included (communitybased vs clinic-based cohorts, prevalent vs incident samples) influenced the prevalence rate and the cognitive profile of patients with PD-MCI.

The aim of this study was to provide a more accurate estimate of the frequency and the profile of cognitive deficits in patients with PD without dementia by employing a common definition for MCI, and analyzing a large, pooled, multicenter cohort of welldefined patients using a standardized method for analysis. The large sample size was also expected to allow a more accurate estimate of PD-MCI in subgroups based on age, gender, and duration and stage of PD.

METHODS Participants. We invited centers that had reported on cognitive functions in relatively large and well-defined cohorts of patients with PD without dementia to participate in this project. Inclusion criteria were sample size $>50$ patients, standardized clinical criteria for the diagnosis of PD and the diagnosis (exclusion) of dementia, and the use of standardized neuropsychological tests with either available norms or inclusion of a control group. Of the 9 centers invited to participate, 7 responded positively and were included (table 1). The pooled data included 8 cohorts. For details regarding case selection and the other procedures, please see the original publications: SouthWestern Norway, 2 cohorts ${ }^{4,5}$; New York, NY ${ }^{6}$; Cambridge, $\mathrm{UK}^{3}$; Newcastle, UK ; Philadelphia, $\mathrm{PA}^{8}$; and Barcelona,
Spain. ${ }^{9} 10$ In addition, one de novo cohort from an outpatient clinic for movement disorders in Napoli, Italy, which has not yet been published, was included. For this cohort, consecutive patients with recently diagnosed PD at the Department of Neuroscience, University of Naples, Italy, were recruited. Patients were either referred by general practitioners or directly contacted the clinic themselves. Inclusion in this cohort required that duration of PD had to be less than 2 years, and familial parkinsonism was excluded.

Diagnosis of dementia. Dementia was diagnosed based on cognitive testing, as well as a clinical interview or a standardized instrument to assess functional impairment due to cognitive dysfunction. The diagnosis of dementia was made according to $D S M-I V$ criteria $^{11}$ in most cases, whereas in one cohort, the new criteria for dementia associated with PD were used. ${ }^{12}$ In 2 cohorts, inclusion of patients without dementia was based on the Mini-Mental State Examination (MMSE), ${ }^{13}$ excluding the bottom 25th age- and education-adjusted percentile on the MMSE ${ }^{8}$ or those with a score $<26^{14}$ (table 1 ). Since the definitions of dementia varied across the centers, we also analyzed the proportion of patients with cognitive impairment in PD without dementia using a uniform definition (i.e., MMSE score $\leq 25$ ) to estimate the presence of dementia in the 1,118 patients where MMSE score was available, along the lines recommended by the MDS Task Force. ${ }^{15}$

Assessment of depression. Assessment of depression by means of a standardized rating scale or a standardized diagnostic interview was performed at all centers (table 1). When rating scales were used we applied the definition of a depressive disorder based on the recent recommendations. ${ }^{16}$ The analyses for presence of MCI were performed twice, once including and once excluding patients with a depressive disorder.

Definition of MCI. A variety of standardized neuropsychological tests were used across the different centers. These tests were allocated to 1 of the 3 cognitive domains: 1) attention/ executive function, 2) memory, or 3) visuospatial functions (table 2). In the event several tests were used for a domain, we chose tests with good psychometric properties, high quality of control data or norms, and minimal missing data. The Barcelona cohort

Table 1 Setting and procedures of the cohorts

\begin{tabular}{|c|c|c|c|c|c|c|}
\hline Center & Setting & $\begin{array}{l}\text { Control } \\
\text { group }\end{array}$ & Cohort & Dementia criteria & PD criteria & $\begin{array}{l}\text { Assessment of } \\
\text { depression }\end{array}$ \\
\hline Cambridge $^{3}$ & Community & No & Prevalent & DSM-IV & UK-PDS BB (30) & BDI \\
\hline Newcastle $^{7}$ & Clinic & Yes & Cross-sectional & DSM-IV + MMSE >25 & UK-PDS BB & MADRS \\
\hline Philadelphia ${ }^{8}$ & Clinic & No & Cross-sectional & $\begin{array}{l}\text { MMSE }>25 \text { th age- and } \\
\text { education- adjusted } \\
\text { percentile }\end{array}$ & Research criteria ${ }^{31}$ & $\begin{array}{l}\text { Semi-structured } \\
\text { interview by trained } \\
\text { research staff }\end{array}$ \\
\hline New York 6 & Community & Yes & Prevalent & DSM-III-R & UK-PDS BB & HDRS \\
\hline Stavanger ${ }^{4}$ & Community & Yes & Prevalent & DSM-III-R & Research $_{\text {criteria }}{ }^{32}$ & MADRS \\
\hline ParkWest ${ }^{18}$ & Community & Yes & Incident & MDS & Research $_{\text {criteria }}{ }^{31}$ & MADRS \\
\hline Barcelona 9,10 & Clinic & Yes & Cross-sectional & $D S M-I V, C D R \geq 1$ & UK-PDS BB & HADS \\
\hline Naples & Clinic & Yes & De novo & DSM-IV and MDS & $\begin{array}{l}\text { UK-PDS BB and } \\
\text { Gelb et al. }{ }^{11}\end{array}$ & GDS-15 \\
\hline
\end{tabular}

Abbreviations: $\mathrm{BDI}=$ Beck Depression Inventory; $\mathrm{CDR}=$ Clinical Dementia Rating; $D S M-I I I-R=$ Diagnostic and Statistical Manual of Mental Disorders, 3rd edition, revised; DSM-IV = Diagnostic and Statistical Manual of Mental Disorders, 4th edition; GDS-15 = Geriatric Depression Scale, 15-item version; HADS = Hospital and Anxiety Depression Scale; HDRS = Hamilton Depression Rating Scale; MADRS = Montgomery and Åsberg Depression Rating Scale; MDS = Movement Disorders Society Task Force Parkinson disease dementia criteria ${ }^{12}$; PD $=$ Parkinson disease; UK-PDS BB $=$ UK Parkinson's Disease Society Brain Bank criteria. ${ }^{30}$ 
Table 2 Overview of cognitive tests used to assess 3 cognitive domains

\begin{tabular}{|c|c|c|c|c|}
\hline \multirow[b]{2}{*}{ Cohort } & \multicolumn{2}{|l|}{ Memory } & \multirow[b]{2}{*}{ Executive/attention } & \multirow[b]{2}{*}{ Visuospatial } \\
\hline & Verbal memory & Visual memory & & \\
\hline Stavanger & DRS: memory & BVRT & $\begin{array}{l}\text { DRS attention, initiation, } \\
\text { Stroop }^{a}\end{array}$ & JOLOT \\
\hline ParkWest & $\begin{array}{l}\text { CVLT-II: immediate and } \\
\text { delayed recall }\end{array}$ & - & $\begin{array}{l}\text { Serial } 7 \mathrm{~s}^{,} \text {, Stroop, }{ }^{\text {a }} \text { fluency: } \\
\text { phonetic + semantic }{ }^{\mathrm{a}}\end{array}$ & $\begin{array}{l}\text { VOSP: cube + } \\
\text { silhouette }\end{array}$ \\
\hline Cambridge & - & $\begin{array}{l}\text { CANTAB: pattern and spatial } \\
\text { recognition memory }\end{array}$ & $\begin{array}{l}\text { Fluency }{ }^{a} \text { phonemic and } \\
\text { semantic Tower of London }\end{array}$ & $\begin{array}{l}\text { Intersecting } \\
\text { pentagons }\end{array}$ \\
\hline Newcastle & $\begin{array}{l}\text { CDR: delayed word } \\
\text { recognition }\end{array}$ & $\begin{array}{l}\text { CDR: delayed picture } \\
\text { recognition }\end{array}$ & $\begin{array}{l}\mathrm{CDR}^{\mathrm{b}} \text { : digit vigilance, } \\
\text { simple and choice reaction } \\
\text { time }\end{array}$ & JOLOT \\
\hline New York & $\begin{array}{l}\text { SRT: total immediate } \\
\text { and delayed recall, } \\
\text { delayed recognition }\end{array}$ & BVRT & $\begin{array}{l}\text { Cancellation test }{ }^{\mathrm{b}} \text { (time, } \\
\text { omissions), fluency } \\
\text { (phonemic and semantic), } \\
\text { similarities }^{\mathrm{a}}\end{array}$ & $\begin{array}{l}\text { Rosen construction, } \\
\text { Benton test } \\
\text { matching }\end{array}$ \\
\hline Philadelphia & $\begin{array}{l}\text { HVLT: immediate total } \\
\text { and delayed recall }\end{array}$ & - & $\begin{array}{l}\text { Fluency }{ }^{\mathrm{a}} \text { : phonemic and } \\
\text { semantic, Stroop, }{ }^{\mathrm{a}} \text { Tower } \\
\text { of London, }{ }^{\mathrm{a}} \text { digit span }\end{array}$ & - \\
\hline Barcelona & $\begin{array}{l}\text { DRS: memory, PD-CRS: } \\
\text { immediate and delayed } \\
\text { recall }\end{array}$ & - & $\begin{array}{l}\text { DRS }^{\text {a }} \text { attention, initiation; } \\
\text { PD-CRS }{ }^{a} \text { fluency, } \\
\text { sustained attention, } \\
\text { working memory }\end{array}$ & $\begin{array}{l}\text { DRS: construction; } \\
\text { PD-CRS: copying } \\
\text { clock }\end{array}$ \\
\hline Naples & $\begin{array}{l}\text { RAVLT: immediate + } \\
\text { delayed recall }\end{array}$ & Rey-Osterrieth figure recall & $\begin{array}{l}\text { Stroop, }{ }^{a} \text { Corsi block span, } \\
\text { fluency }{ }^{\mathrm{b}} \text { (phonemic and } \\
\text { semantic Trail-Making } \\
\text { Test }^{\mathrm{b}} \text {, verbal span }{ }^{\mathrm{b}} \text { ) }\end{array}$ & $\begin{array}{l}\text { Rey-Osterrieth } \\
\text { copy, JOLOT }\end{array}$ \\
\hline
\end{tabular}

Abbreviations: BVRTr/m = Benton Visual Retention Test retention/matching; CAMCOG $=$ the cognitive and self-contained part of the Cambridge Examination for Mental Disorders of the Elderly; CANTAB = Cambridge Neuropsychological Automated Testing Battery; CDR = Cognitive Drug Research; CVLT-2 = California Verbal Learning Test II; DRS = Dementia Rating Scale; HVLT = Hopkins Verbal Learning Test; JOLOT = Judgment of Line Orientation Test; PD-CRS = Parkinson's Disease Cognitive Rating Scale; RAVLT = Rey Auditory Verbal Learning Test; SRT = Selective Reminding Test; VOSP = Visual Object Space Perception Test.

${ }^{a}$ Executive functioning subdomain.

${ }^{\mathrm{b}}$ Attention subdomain.

was assessed using 2 cognitive screening batteries which provide subscores for different cognitive domains: Dementia Rating Scale $^{17}$ and Parkinson's Disease Cognitive Rating Scale (PDCRS). ${ }^{9}$ Not all patients had tests assessing each domain; all of them, however, had data on at least 2 domains. The number of patients with data available for each domain were 1,341 (memory), 1,329 (attention/executive), and 1,141 (visuospatial).

The definition for cognitive impairment was based on performance in the 3 cognitive domains. For this purpose $Z$ scores were calculated for each cognitive domain using the raw data provided by each site. The cognitive domain $Z$ scores were the average $Z$ scores of the tests included in that domain. For datasets with control groups, the $Z$ scores for each test were calculated based on control group performance. In order to adjust for age, education, and sex of the individual patient, a multiple regression analysis was performed in the control group, employing the domain $Z$ scores as dependent variables and age, sex, and education as independent variables as previously reported. ${ }^{18}$ The resulting intercept and regression weights were then used to calculate expected cognitive domain scores for each patient and control. For datasets or individual tests lacking control data, published normative data were used to calculate $Z$ scores, correcting for age and education where possible.

Patients with PD were classified as having MCI if the difference between the actual cognitive domain $Z$ score and the expected score on at least 1 out of 3 cognitive domains was below -1.5 (i.e., similar to a score 1.5 standard deviations below the population mean) based on the comparison between patients and controls at each site. ${ }^{18}$ Subjects with MCI were further clas- sified into 1 of the following 4 subtypes using a previously proposed algorithm ${ }^{19}: 1$ ) amnestic single-domain MCI (aMCI-SD); 2) amnestic multiple-domain MCI (aMCI-MD); 3) nonamnestic single-domain MCI (naMCI-SD); or 4) nonamnestic multiple-domain MCI (naMCI-MD).

Tests used to nominally assess attention or executive functions were merged for the purpose of this analysis, as some of the tests used either to assess attention or executive functions overlap in terms of the basic cognitive processes they involve. In addition, by increasing the number of tests in each domain, the reliability of the results for that domain increases. In an attempt to separate core attentional functions from the more complex executive functions, we also performed an additional analysis in which tests were allocated to one or the other function based on their face validity. Not all patients, however, had data on attention and executive function tests; therefore these subanalyses were performed in 691 and 1,229 patients. In case more than one test was performed, mean $Z$ scores were calculated, yielding mean age- and education-corrected $Z$ scores for these subdomains.

Statistical analyses. Analyses were performed to calculate the proportion of patients with impairment in any cognitive domain, including 95\% confidence intervals (CIs), using Vassar online program (http://faculty.vassar.edu/lowry/VassarStats.html). Comparisons between cohorts from different centers were made using one-way analysis of variance, Kruskal-Wallis, or $\chi^{2}$ tests as appropriate. To identify clinical correlates of MCI, between-group comparisons were made using Student $t$ test or $\chi^{2}$ test. Variables 
Table $3 \quad$ Frequency of $\mathrm{MCl}$ and other characteristics in study cohorts ${ }^{\mathrm{a}}$

\begin{tabular}{|c|c|c|c|c|c|c|c|c|c|c|c|c|}
\hline Cohort & No. & $\begin{array}{l}\% \\
\text { Male }\end{array}$ & $\begin{array}{l}\text { Age, } \\
y\end{array}$ & Duration & MMSE & $\begin{array}{l}\text { UPDRS } \\
\text { III }\end{array}$ & $\begin{array}{l}\text { L-DOPA } \\
\text { dose }\end{array}$ & $\begin{array}{l}\text { Dopamine } \\
\text { agonist, \% }\end{array}$ & $\begin{array}{l}\text { Antidepressants, } \\
\%\end{array}$ & $\begin{array}{l}\text { Antipsychotics, } \\
\%\end{array}$ & $\begin{array}{l}\% \\
\mathrm{MCl}\end{array}$ & $95 \% \mathrm{Cl}$ \\
\hline Newcastle & 109 & 60.0 & 70.2 & 7.1 & 27.1 & 17.8 & 322 & 23.9 & 24.6 & 0 & 29.4 & $21.6-38.5$ \\
\hline Philadelphia & 170 & 64.4 & 63.5 & 7.7 & 29.1 & 20.5 & 467 & 52.9 & 31.2 & 1.2 & 24.7 & $18.8-31.7$ \\
\hline New York & 173 & 46.8 & 74.4 & 6.8 & ND & 25.0 & 359 & 27.2 & 9.8 & 1.7 & 21.4 & $15,9-28.1$ \\
\hline Stavanger & 71 & 46.5 & 71.3 & 11.7 & 28.7 & 21.4 & 672 & 18.8 & 15.5 & 0 & 39.4 & 28.9-51.1 \\
\hline Barcelona & 157 & 59.5 & 68.6 & 7.4 & 28.1 & 22.0 & 712 & 62.0 & 20.2 & 3.8 & 19.7 & $14.3-26.7$ \\
\hline Naples & 56 & 55.4 & 59.3 & 1.5 & 27.4 & 14.8 & 0 & 0 & 0 & 0 & 28.6 & $18.4-41.5$ \\
\hline All & 1,346 & 59.8 & 67.5 & 6.1 & 28.2 & 21.6 & 457 & 37.1 & 17.1 & 1.6 & 25.8 & $23.5-28.2$ \\
\hline
\end{tabular}

Abbreviations: $\mathrm{Cl}$ = confidence interval; $\mathrm{MCl}=$ mild cognitive impairment; MMSE = Mini-Mental State Examination; UPDRS III = Unified Parkinson's Disease Rating Scale, motor subscale.

a Numbers represent means if not otherwise stated.

that were significantly associated with MCI in the bivariate analysis were included in a subsequent multivariate logistic regression model, using the presence of MCI as the dependent variable and Unified Parkinson's Disease Rating Scale (UPDRS) motor score, center, depression, gender, and age as independent variables. To explore the potential effect of attentional impairment on memory we ran 2 multivariate linear regression models with memory $\mathrm{Z}$ score as the dependent variable. In the first model, only group was included as independent variable, and in the second model, attention/executive $Z$ score was entered first and then followed by group. SPSS version 15.0 was used for these analyses and $p<0.05$ was considered statistically significant.

RESULTS Frequency and profile of MCI. A total of 1,346 patients without dementia were included in the analysis. The characteristics of the cohorts are shown in table 3. A total of 347 patients $(25.8 \%$ [95\% CI 23.5-28.2]) were classified as having MCI. The proportion of patients with MCI differed between centers $\left(\chi^{2}=21.4[d f=7], p=0.003\right)$, even after adjusting for UPDRS motor score and disease duration in a logistic regression analysis $(p=0.007)$. The lowest proportion was found in the incident, unmedicated, community-based cohort (18.9\%; $14.0-24.9)$, and the highest proportion was found in a prevalence-cohort with advanced PD (39.4\%; 28.9-51.1) (table 3).

Among the 3 cognitive domains, memory impairment was the most common deficit (13.3\%; $11.6-$ 15.3), followed by visuospatial impairment (11.0\%; 9.4-13.0) and then attention/executive function impairment $(10.1 \%$; 8.6-11.9). Impairment in only 1 of the 3 domains occurred in $19.5 \%(17.4-21.7)$ of patients, $5.4 \%$ (4.3-6.8) had impairment in 2 domains, and $0.9 \%(0.5-1.6)$ in all 3 domains. The mean $Z$ scores at each center are shown in table e- 1 on the Neurology ${ }^{\circledR}$ Web site at www.neurology.org. With regard to the MCI subtypes, 152 (11.3\%; 9.713.1) had naMCI-SD, $112(8.9 \% ; 7.0-9.9)$ had
aMCI-SD, 65 (4.8\%; 3.8-6.1) aMCI-MD, and 18 $(1.3 \% ; 0.9-2.1)$ had naMCI-MD. Although memory was the most commonly affected single domain, naMCI-SD was more common than aMCI-SD. Among the 152 subjects with naMCI-SD, 79 $(52.0 \%)$ had attention/executive function impairment, and $54.8 \%$ (51 of 93 with visuospatial testing) had visuospatial impairment.

The separate analysis of attention and executive functions revealed that $9.6 \%$ and $9.4 \%$ of patients had impaired attentional and executive function scores, with a more impaired executive score (mean $Z$ score -0.24 , SD 0.8$)$ compared to attention score $(-0.04,1.1)(t=-4.3$, df 581, $p<0.0005)$. Although there was a correlation between memory and attention/executive function $Z$ scores $(r=0.36, p<$ $0.0005)$, in a linear regression analysis an effect of group (i.e., PD vs NC) on memory performance was still evident after controlling for attention/executive function $Z$ score in the model ( $p<0.0005)$.

Using the arbitrary definition of MMSE score $\leq 25$ as the criterion to exclude patients with possible dementia, 25.3\% (95\% CI; 22.9-27.9) of remaining patients were classified as having MCI, a figure very similar to the main analysis. The proportion with MCI differed between the centers $\left(\chi^{2}=21.4, d f=\right.$ $6, p=0.002)$ also in this analysis.

Correlates of MCI. Comparing patients with and without MCI, we found that MCI was associated with increasing age at the time of assessment and at disease onset, increasing duration of disease, severity of motor symptoms and disease stage, presence of depression, and lower proportion of dopamine agonist use (table 4). Within the MCI subtypes, there were no gender or age differences, whereas those with amnestic and nonamnestic multiple-domain MCI had more severe motor symptoms than those with 


\begin{tabular}{|llll|}
\hline Table 4 & $\begin{array}{l}\text { Clinical and demographic } \\
\text { characteristics of patients with and } \\
\text { without MCl }\end{array}$ \\
\hline MCI & No MCI & p \\
\hline Age & $69.6(8.6)$ & $66.8(10.5)$ & $<0.0005$ \\
MMSE & $27.3(2.3)$ & $28.6(1.7)$ & $<0.0005$ \\
Age at onset & $62.0(9.9)$ & $59.7(11.2)$ & 0.002 \\
Disease duration & $6.8(5.3)$ & $5.9(4.8)$ & 0.002 \\
UPDRS motor & $25.7(13.7)$ & $20.1(11.1)$ & $<0.0005$ \\
Hoehn \& Yahr & $2.1(0.8)$ & $1.0(0.7)$ & $<0.0005$ \\
Gender & & & 0.09 \\
\hline Male & 63.7 & 58.6 & \\
\hline Female & 36.3 & 41.4 & \\
\hline Depression & 17.9 & 9.7 & $<0.0005$ \\
\hline L-DOPA dose & $484(354)$ & $448(375)$ & 0.17 \\
\hline Dopamine agonist & 38.5 & 33.6 & 0.017 \\
\hline Anti-depressant & 20.2 & 16.6 & 0.4 \\
\hline
\end{tabular}

Abbreviations: $\mathrm{MCl}=$ mild cognitive impairment; MMSE = Mini-Mental State Examination; UPDRS = Unified Parkinson's Disease Rating Scale.

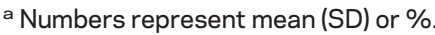

single-domain MCI (1-way analysis of variance: $F=$ 6.5, $p<0.0005)$.

In the logistic regression analyses, UPDRS motor score $(p<0.0005)$, center $(p=0.009)$, depression $(p=0.023)$, gender $(p<0.05)$, and age $(p<$ $0.0005)$ remained independently associated with MCI, whereas the effects of use of dopamine agonists did not reach significance. Using Hoehn \& Yahr stage instead of total UPDRS motor score as a measure of disease severity, Hoehn \& Yahr was still significantly associated with MCI. Similarly, when age was replaced with age at onset, it was also significantly associated with MCI. However, when age was replaced by duration of disease, it was not significantly associated with MCI.

DISCUSSION This analysis of a large database pooled from 8 different cohorts revealed that approximately one-quarter of patients with PD without dementia have impairment in at least 1 cognitive domain, defined as 1.5 times worse performance on $Z$ scores, as compared to controls or normative data. Given the increased risk for more rapid cognitive decline and dementia in patients with PD with MCI, this finding highlights the importance of careful monitoring of cognitive functions in patients without dementia.

There were differences in the frequency of MCI across the centers, even after adjusting for possible confounders. Along with differences in methodology and the sensitivity of individual neuropsychological tests used, these differences may also be due to variations in patient populations: for instance, the lowest prevalence of MCI was found in the incident, unmedicated, community-based cohort (18.9\%), which probably represents patients in the earliest stages of the disease.

The most common MCI subtype was nonamnestic, single-domain MCI (11.3\%), followed by amnestic single-domain MCI (8.9\%). However, across the different types of MCI, memory was the most commonly impaired domain (13.3\%); Thus, memory impairment represents an important aspect of the early cognitive syndrome in PD, consistent with previous findings in patients with $\mathrm{PD}$ with dementia and in patients with PD without dementia.

The mechanism of the memory impairment (limbic type storage failure vs retrieval deficits) cannot be discerned from the current data. As has previously been pointed out, ${ }^{20,21}$ part of the memory impairment in PD may be secondary to impaired attention and executive dysfunction, although recent studies suggest that memory encoding may also be impaired in PD. ${ }^{22,23}$ Our analyses also confirmed memory was still impaired in PD even after adjusting for the effect of impaired attention/executive functioning. Impairment in attention/executive functions has been described to constitute one of the core impaired cognitive domains in the previous studies, as was the case also in this study. The separate analysis of attention and executive functions revealed that simpler attentional measures are relatively less impaired compared with more complex executive functions.

It has been recently suggested that frontal executive and posterior cortical cognitive syndromes in PD can be separable in terms of both their genetic basis and relationship to development of dementia. ${ }^{3}$ The present results showed that impairment in attentional/executive tasks may not always be the predominant deficit in PD-MCI, highlighting the importance for future interventional studies to select instruments which adequately explore also posterior cortical functions. ${ }^{24}$

MCI was significantly and independently associated with older age at assessment and disease onset, longer disease duration, more severe motor symptoms, more advanced disease stage, and lower overall cognition. Depression is common in PD, and depressed patients with $\mathrm{PD}$ have more cognitive impairment than nondepressed patients. ${ }^{25} \mathrm{We}$ also found that MCI was more common in depressed than nondepressed patients; the overall frequency of depression in both populations was, however, relatively low, suggesting that overall depression is not a major contributor to MCI in PD.

There are several limitations to our study. Dopaminergic drugs may affect cognitive functioning; only 2 of the cohorts in this analysis included un- 
medicated, de novo patients. However, the proportion with $\mathrm{MCI}$ in these 2 cohorts did not differ from the frequency in some of the cohorts which received dopaminergic medications. Second, the recruitment base and method were not homogeneous across the centers. The pooled cohort thus included patients without dementia at various stages of the disease, as well as prevalent and incident cohorts. On the other hand, inclusion of different cohorts in the analysis also constituted an advantage, as it allowed for the evaluation of a broader spectrum of patients without dementia.

Third, different criteria for dementia were used across the various centers. As the proportion with MCI is influenced by the definition of dementia, a broader definition might include some patients in the more severe end of MCI being classified as dementia, whereas a more restrictive definition may leave these patients in the MCI group. We attempted to deal with this ambiguity by also using an arbitrary, yet uniform, criterion for dementia (i.e., MMSE score $\leq 25$ ). In this subanalysis the proportion of patients with MCI was similar to the results of the main analysis, suggesting that the use of different dementia criteria did not meaningfully influence the results. Finally, the MCI definition used in this study was based entirely on cognitive testing. The original MCI definition requires presence of subjective cognitive complaints (preferably corroborated by a third party), objective evidence of impaired test performance, and lack of significant functional impairment. ${ }^{26}$ Identifying reliable subjective cognitive impairment in patients with PD without dementia, however, has proven to be difficult. Studies exploring this feature have found both overreporting (i.e., patients with normal test scores reporting subjective impairment) and underreporting (i.e., patients with impaired scores reporting normal cognition). ${ }^{18,27}$ Hence, the presence or absence of subjective cognitive complaints was not included as part of the MCI definition in this analysis, also due to the lack of any universally accepted criteria for MCI in PD.

Since different tests were used in different cohorts, they were allocated to 3 broad cognitive domains and $Z$ scores were calculated. This enabled us to combine data from different studies and explore main cognitive functions in a large sample size. With this approach, however, it was not possible to explore individual cognitive mechanisms (such as the mechanism of memory impairment) in more detail. Another shortcoming is a certain amount of missing data, particularly for the visuospatial assessment. This might have influenced our findings to some extent, in that MCI diagnosis might have changed from single to multiple domains or even from a nor- mal control to a single-domain MCI in some patients if more data were included.

There is a need to define standardized diagnostic criteria for MCI in PD, and future studies should further explore whether different subtypes of MCI have different underlying pathologies and risk for progression to dementia. Most importantly, since drug treatment can improve cognition in dementia associated with $\mathrm{PD},{ }^{28,29}$ clinical trials to explore whether these or other medications might improve cognitive deficits or delay the progression from MCI to dementia in PD are now a priority.

\section{AUTHOR CONTRIBUTIONS}

Statistical analysis was conducted by Dr. Bronnick and Dr. Aarsland.

\section{DISCLOSURE}

Dr. Aarsland serves on scientific advisory boards for Lundbeck Inc. and Merck Serono; has received funding for travel and speaker honoraria from Lundbeck Inc., Novartis, GE Healthcare, and GlaxoSmithKline; serves on the editorial boards of International Psychogeriatrics, Movement Disorders, and the Journal of Neurology, Neurosurgery, and Psychiatry; and receives research support from Lundbeck Inc. and Merck Serono. Dr. Brønnick has received funding for travel and speaker honoraria from Solvay Pharmaceuticals, Inc. Dr. Williams-Gray has received research support from the Parkinson's Disease Society and the Patrick Berthoud Trust. Dr. Weintraub has served on scientific advisory boards for Boehringer Ingelheim, ACADIA Pharmaceuticals, Novartis, Osmotica Pharmaceutical Corp., BrainCells Inc., Merck Serono, Sanofi-Aventis, GE Healthcare, Johnson \& Johnson, and Solvay Pharmaceuticals, Inc.; serves on the editorial board of Movement Disorders; has received speaker honoraria from Boehringer Ingelheim and Pfizer Inc.; has received/receives research support from Boehringer Ingelheim, the NIH (NIMH K23 MH067894 [PI], NINDS P50 NS053488-01 [coinvestigator], NIA RO1AG031348 [site PI], and NINDS R01NS065087 [coinvestigator]), and the Michael J. Fox Foundation for Parkinson's Research; and receives payments from the University of Pennsylvania for licensing of Questionnaire for Impulsive-Compulsive Disorders in Parkinson's Disease. Dr. Marder serves on the editorial board of Neurology ${ }^{\circledR}$ and receives research support from Amarin Corporation, Boehringer Ingelheim NeuroSearch, the NIH (NS36630 [PI], 1UL1 RR024156-01 [Director PCIR], PO412196-G [coinvestigator], and PO412196-G [coinvestigator]), the Parkinson Disease Foundation, the Huntington's Disease Society of America, and the Parkinson Study Group. Dr. Kulisevsky has served on scientific advisory boards for Merck Serono and Servier; has received honoraria from Merck Serono, Novartis, Lundbeck Inc., and Schwartz Biomedical, LLC.; serves as an Associate Editor for Revista de Neurología; and receives research support from Lundbeck Inc. and Instituto de Salud Carlos III, Spain. Dr. Burn serves on scientific advisory boards for Teva Pharmaceutical Industries Ltd. and Merck Serono; serves as a consultant for Archimedes, Inc.; serves as an Associate Editor for the Movement Disorder Journal; has received speaker honoraria from Teva Pharmaceutical Industries Ltd./Lundbeck Inc., Orion Corporation, Boehringer Ingelheim, GlaxoSmithKline, Novartis, and UCB; and has received research support from the Wellcome Trust, the NIHR Health Technology Assessment Programme, the Michael J Fox Foundation, and the Parkinson's Disease Society. Dr. Barone serves on scientific advisory boards for and has received funding for travel and speaker honoraria from Boehringer Ingelheim, Merck Serono, Novartis, UCB, and Lundbeck Inc.; serves as an Associate Editor for the Journal of Neurodegenerative Disorders and Parkinson's Europe; and receives research support from Boehringer Ingelheim, Merck Serono, Novartis, UCB, Lundbeck Inc., and Solvay Pharmaceuticals, Inc. Dr. Pagonabarraga has served on a scientific advisory board for Novartis and has received honoraria from Boehringer Ingelheim, Novartis, Janssen, Lundbeck Inc., GlaxoSmithKline, and Schwartz Biomedical, LLC. Dr. Allcock holds stock in the $\mathrm{C} / \mathrm{N}$ Group, Inc. Dr. Santangelo reports no 
disclosures. Dr. Foltynie has served on a scientific advisory board for Solvay Pharmaceuticals, Inc.; has received funding for travel or speaker honoraria from Teva Pharmaceutical Industries Ltd., MDS Nordion, GlaxoSmith Kline, and Orion Corporation; and has received research support from the Parkinson's Disease Society, Brain Research Trust, and Parkinson's Appeal. Dr. Janvin reports no disclosures. Dr. Larsen has served on scientific advisory boards for Lundbeck Inc. and GlaxoSmithKline; has received speaker honoraria from GlaxoSmithKline; and receives research support from the Western Norway Health Trust, the Norwegian Research Counsel, and the Norwegian Parkinson's disease Association. Dr. Barker serves on scientific advisory boards for and has received speaker honoraria from Teva Pharmaceutical Industries Ltd. and Lundbeck Inc.; serves as co-editor-in-Chief for the Journal of Neurology and ACNR and on the editorial board of Synapse, Cell Transplantation and Regenerative Medicine; receives royalties from the publication of Neuroscience at a Glance (Blackwell Publishing, 1999); and receives research support from the Parkinson's Disease Society, Wellcome Trust, the UK Medical Research Council, and NIHR Biomedical research award to Addenbrooke's University Hospital. Dr. Emre serves on scientific advisory boards for Merck Serono, Novartis, Schering-Plough Corp., Teva Pharmaceutical Industries Ltd./ Lundbeck Inc., Orion Corporation, Noscira, and AC Immune SA; has received funding for travel from Lundbeck Inc.; serves on the editorial board of Practical Neurology; receives royalties from the publication of Parkinson Hastalýý (Gunes Tip Kitapevi, 2009) and Dementia in Parkinson's Disease (Oxford University Press, 2010); has received speaker honoraria from Novartis, Lundbeck Inc., Orion Corporation, Pfizer Inc., and Boehringer Ingelheim; and receives/has received research support from Novartis, Lundbeck Inc., and Eli Lilly and Company.

Received February 22, 2010. Accepted in final form May 12, 2010.

\section{REFERENCES}

1. Janvin CC, Larsen JP, Aarsland D, Hugdahl K. Subtypes of mild cognitive impairment in Parkinson's disease: progression to dementia. Mov Disord 2006;21:1343-1349.

2. Williams-Gray CH, Foltynie T, Brayne CE, Robbins TW, Barker RA. Evolution of cognitive dysfunction in an incident Parkinson's disease cohort. Brain 2007;130:17871798.

3. Williams-Gray CH, Evans JR, Goris A, et al. The distinct cognitive syndromes of Parkinson's disease: 5 year follow-up of the CamPaIGN cohort. Brain 2009;132: 2958-2969.

4. Janvin C, Aarsland D, Larsen JP, Hugdahl K. Neuropsychological profile of patients with Parkinson's disease without dementia. Dement Geriatr Cogn Disord 2003;15: 126-131.

5. Alves G, Muller B, Herlofson K, et al. Incidence of Parkinson's disease in Norway: the Norwegian ParkWest study. J Neurol Neurosurg Psychiatry 2009;80:851-857.

6. Levy G, Jacobs DM, Tang MX, et al. Memory and executive function impairment predict dementia in Parkinson's disease. Mov Disord 2002;17:1221-1226.

7. Allcock LM, Kenny RA, Mosimann UP, et al. Orthostatic hypotension in Parkinson's disease: association with cognitive decline? Int J Geriatr Psychiatry 2006; 21:778-783.

8. Weintraub D, Moberg PJ, Culbertson WC, Duda JE, Katz IR, Stern MB. Dimensions of executive function in Parkinson's disease. Dement Geriatr Cogn Disord 2005;20: $140-144$.

9. Pagonabarraga J, Kulisevsky J, Llebaria G, GarciaSanchez C, Pascual-Sedano B, Gironell A. Parkinson's disease-cognitive rating scale: a new cognitive scale specific for Parkinson's disease. Mov Disord 2008;23:998 1005.
10. Llebaria G, Pagonabarraga J, Kulisevsky J, et al. Cut-off score of the Mattis Dementia Rating Scale for screening dementia in Parkinson's disease. Mov Disord 2008;23: 1546-1550.

11. American Psychiatric Association. Diagnostic and Statistical Manual of Mental Disorders: DSM-IV (Text Revision). Washington, DC: American Psychiatric Association; 2000.

12. Emre M, Aarsland D, Brown R, et al. Clinical diagnostic criteria for dementia associated with Parkinson's disease. Mov Disord 2007;22:1689-1707.

13. Folstein MF, Folstein SE, McHugh PR. "Mini-mental state": a practical method for grading the cognitive state of patients for the clinician. J Psychiatr Res 1975;12:189198.

14. Allcock LM, Ullyart K, Kenny RA, Burn DJ. Frequency of orthostatic hypotension in a community based cohort of patients with Parkinson's disease. J Neurol Neurosurg Psychiatry 2004;75:1470-1471.

15. Dubois B, Burn D, Goetz C, et al. Diagnostic procedures for Parkinson's disease dementia: recommendations from the movement disorder society task force. Mov Disord 2007;22:2314-2324.

16. Schrag A, Barone P, Brown RG, et al. Depression rating scales in Parkinson's disease: critique and recommendations. Mov Disord 2007;22:1077-1092.

17. Mattis S. Dementia Rating Scale. In: Bellak L, Karasu TB, eds. Geriatric Psychiatry: A Handbook for Psychiatrists and Primary Care Physicians. New York: Grune and Stratton; 1976.

18. Aarsland D, Bronnick K, Larsen JP, Tysnes OB, Alves G. Cognitive impairment in incident, untreated Parkinson disease: the Norwegian ParkWest study. Neurology 2009; 72:1121-1126.

19. Winblad B, Palmer K, Kivipelto M, et al. Mild cognitive impairment: beyond controversies, towards a consensus: report of the International Working Group on Mild Cognitive Impairment. J Intern Med 2004;256:240-246.

20. Troster AI. Neuropsychological characteristics of dementia with Lewy bodies and Parkinson's disease with dementia: differentiation, early detection, and implications for "mild cognitive impairment" and biomarkers. Neuropsychol Rev 2008;18:103-119.

21. Dubois B. Is PD-MCI a useful concept? Mov Disord 2007;22:1215-1216

22. Weintraub D, Moberg PJ, Culbertson WC, Duda JE, Stern MB. Evidence for impaired encoding and retrieval memory profiles in Parkinson disease. Cogn Behav Neurol 2004;17:195-200.

23. Whittington CJ, Podd J, Stewart-Williams S. Memory deficits in Parkinson's disease. J Clin Exp Neuropsychol 2006;28:738-754.

24. Kulisevsky J, Pagonabarraga J. Cognitive impairment in Parkinson's disease: tools for diagnosis and assessment. Mov Disord 2009;24:1103-1110.

25. Santangelo G, Trojano L, Vitale C, et al. A neuropsychological longitudinal study in Parkinson's patients with and without hallucinations. Mov Disord 2007;22: $2418-2425$.

26. Petersen RC, Smith GE, Waring SC, Ivnik RJ, Tangalos EG, Kokmen E. Mild cognitive impairment: clinical characterization and outcome. Arch Neurol 1999;56: 303-308. 
27. Caviness JN, Driver-Dunckley E, Connor DJ, et al. Defining mild cognitive impairment in Parkinson's disease. Mov Disord 2007;22:1272-1277.

28. Aarsland D, Ballard C, Walker Z, et al. Memantine in patients with Parkinson's disease dementia or dementia with Lewy bodies: a double-blind, placebo-controlled, multicentre trial. Lancet Neurol 2009;8:613-618.

29. Emre M, Aarsland D, Albanese A, et al. Rivastigmine for dementia associated with Parkinson's disease. N Engl J Med 2004;351:2509-2518.
30. Hughes AJ, Daniel SE, Kilford L, Lees AJ. Accuracy of clinical diagnosis of idiopathic Parkinson's disease: a clinico-pathological study of 100 cases. J Neurol Neurosurg Psychiatry 1992;55:181-184.

31. Gelb DJ, Oliver E, Gilman S. Diagnostic criteria for Parkinson disease. Arch Neurol 1999;56:33-39.

32. Larsen JP, Dupont E, Tandberg E. Clinical diagnosis of Parkinson's disease: proposal of diagnostic subgroups classified at different levels of confidence. Acta Neurol Scand 1994;89:242-251.

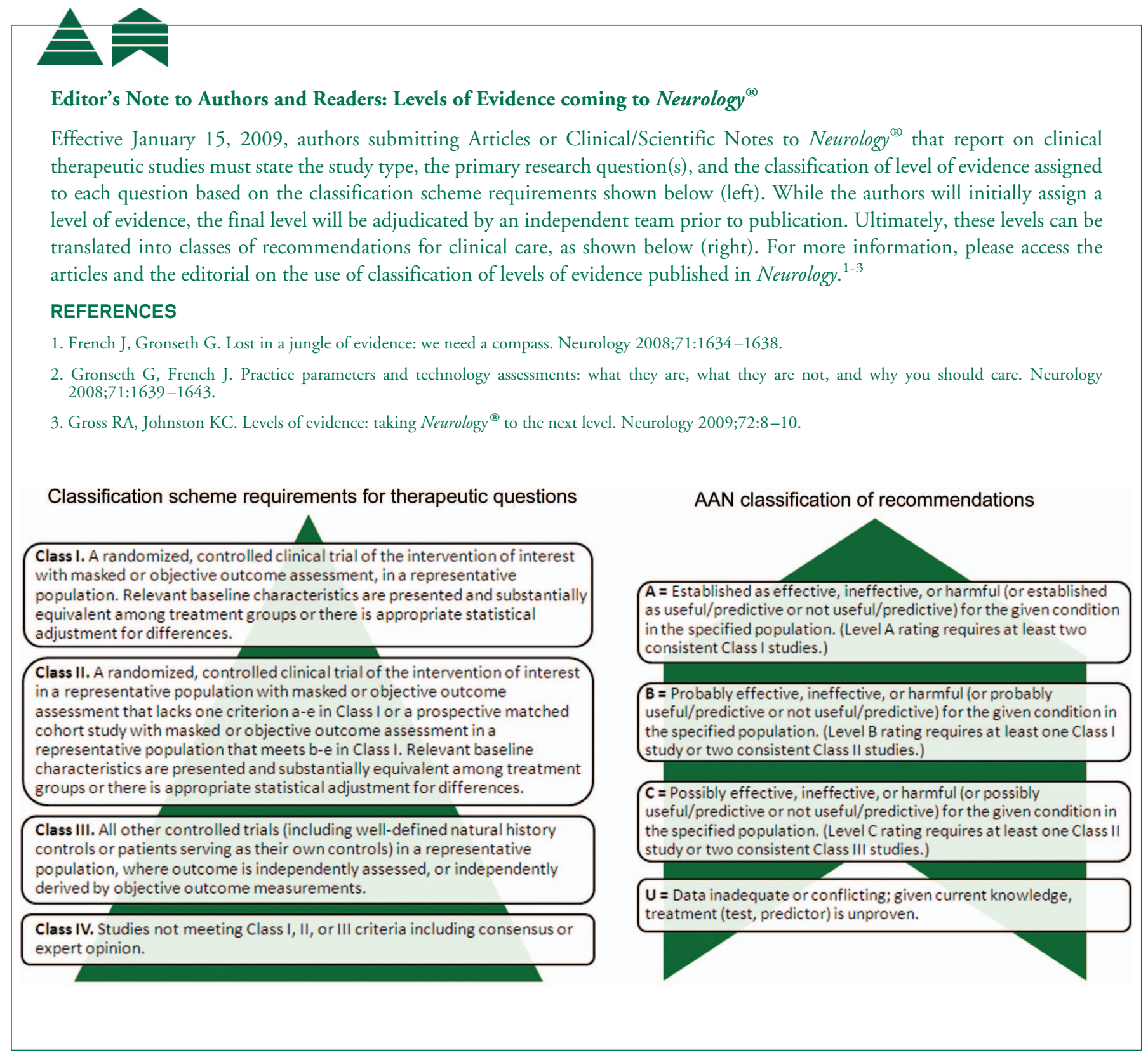

